\title{
Silicone Breast Implants as Predisposing Factor for Non-Hodgkin's Lymphoma: An Additional Facet of Auto-Inflammatory Syndrome Induced by Adjuvant
}

\author{
Idan Goren ${ }^{\mathrm{a}, \mathrm{d}}$, Dana Doron ${ }^{\mathrm{a}}$, Orith Portnoy ${ }^{\mathrm{b}}$, Yehuda Shoenfeld ${ }^{\mathrm{c}}$, Gad Segal ${ }^{\mathrm{a}}$
}

\begin{abstract}
Autoimmune disorders are already established as risk factors for later development of lymphoproliferative disease, i.e. non-Hodgkin's lymphoma (NHL). The recently defined autoimmunity syndrome induced by adjuvants (ASIA syndrome) involves autoimmunity ignited by the mere presence of various adjuvants (e.g. components of certain vaccines) triggering autoimmunity. A causative relation between ASIA-related autoimmunity and later development of NHL has not yet been shown. The current case presents a 77-year-old patient, diagnosed to have NHL 13 years following cosmetic bilateral breast augmentation (with silicone implants) surgery. The authors regard the silicone implants of this patient as the trigger for ASIA syndrome later causing her subsequent lymphoproliferative disease.
\end{abstract}

Keywords: Lymphoma; Silicone implants; Auto-inflammatory syndrome induced by adjuvant; Autoimmunity; Autoimmune hemolytic anemia

\section{Introduction}

Autoimmunity is an established risk factor for lymphoproliferative disorders [1], of which non-Hodgkin lymphoma (NHL) is of worst outcomes. In recent years several case studies and case series linked the occurrence of NHL with

\footnotetext{
Manuscript accepted for publication June 9, 2014

${ }^{a}$ Department of Internal Medicine T, Sheba Medical Center, Tel Hashomer, Israel; Sackler School of Medicine, Tel Aviv University, Tel Aviv, Israel

${ }^{\mathrm{b}}$ Department of Diagnostic Imaging, Sheba Medical Center, Tel Hashomer, Israel

${ }^{c}$ Zabludowicz Center for Autoimmune Diseases, Sheba Medical Center, Tel Hashomer, Israel

${ }^{\mathrm{d}}$ Corresponding Author: Idan Goren, Department of Internal Medicine

T, Sheba Medical Center, Tel Hashomer, Israel.

Email: Idan.goren@sheba.health.gov.il

doi: http://dx.doi.org/10.14740/jmc1828w
}

the presence of silicone breast implants, as in the case of breast anaplastic large cell lymphoma of the T-cell origin (ALCL) and the cutaneous T-cell lymphoma [2]. Recently, the FDA published a safety communication regarding a suggested association between anaplastic lymphoma kinasenegative ALCL and silicone breast implant [3]. The exact mechanism linking the two has yet to be elucidated. A possible "missing link" between the cause and the effect might be ASIA syndrome ignited by the silicone breast implants.

We describe herein a case of a 77-year-old woman hospitalized due to symptomatic, autoimmune hemolytic anemia. Her anemia was found to be associated with a retroperitoneal-seated NHL. Thirteen years prior to hospitalization, she went through a cosmetic bilateral breast augmentation with silicone implants. We suggest that the autoimmune/inflammatory syndrome induced by adjuvants, ASIA syndrome [4], is the "missing link" between the patient's implants and her subsequent lymphoma.

\section{Case Report}

A 77-year-old woman was hospitalized due to symptomatic anemia. Her past medical history included arterial hypertension and dyslipidemia, total abdominal hysterectomy with bilateral salpingo-oophorectomy 20 years ago, and cosmetic bilateral breast augmentation with silicone implants 13 years prior to the present hospitalization. For the past 10 years, she complained of bilateral hip and knee joints pain for which she underwent several injections for pain relief by an orthopedic surgeon. Upon admission, the patient complained of generalized weakness, loss of appetite for the past 2 months and a single episode of pre-syncope. She was febrile but denied having night sweats, loss of weight or other "B" symptoms. Physical examination was unremarkable except for an aortic valve ejection (grade 3) murmur. Neither lymphadenopathy nor hepato-splenomegaly was detected. Leukocytes and platelet counts were normal; hemoglobin concentration was $7.0 \mathrm{~g} / \mathrm{dL}$ with normal mean corpuscular volume and mean corpuscular hemoglobin values. Blood chemistry was unremarkable except for an elevated creatinine and lactate dehydrogenase concentrations $(1.32 \mathrm{mg} / \mathrm{dL}$ and $430 \mathrm{IU} / \mathrm{L}$ re- 

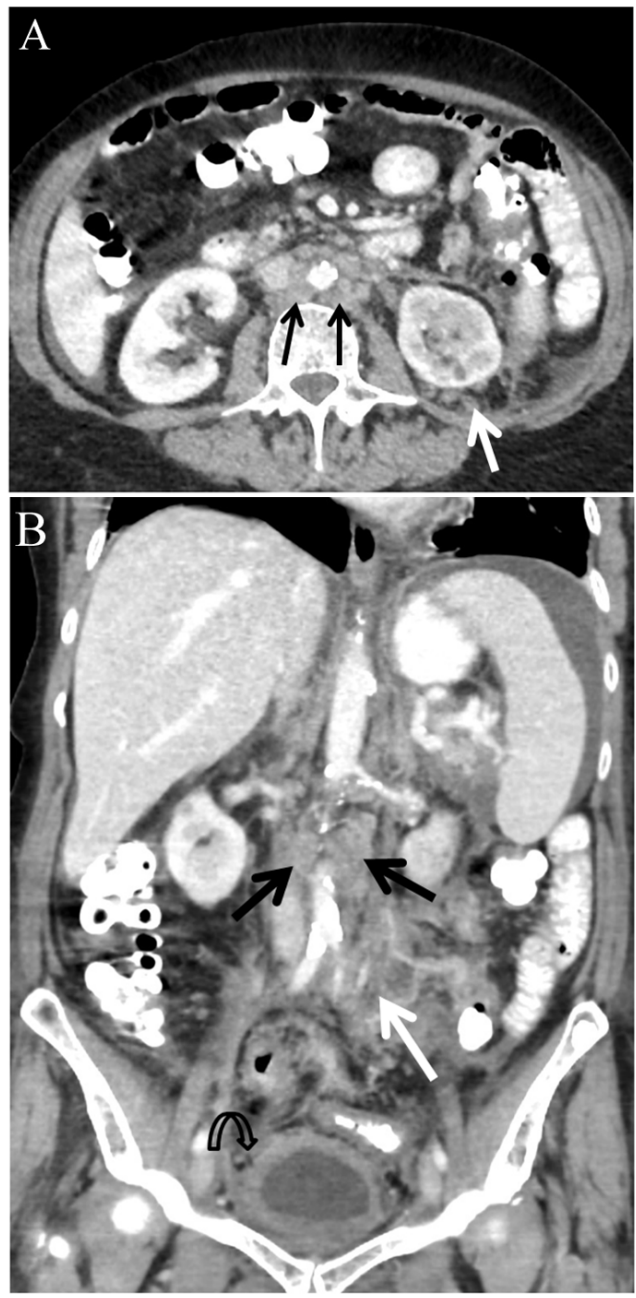

Figure 1. Abdominal CT scan with intravenous contrast injection. Para-aortic lymphadenopathy (black arrows) and left retroperitoneal and mesenteric root soft tissue infiltration (white arrows). Bladder wall thickening (curved arrow) and ascites seen at upper abdomen. (A) Axial slice at mid-abdomen. (B) Coronal image.

spectively). Anemia work-up revealed increased reticulocyte index, a very low haptoglobin concentration and a positive direct Coombs' test.

Preliminary test results were consistent with an autoimmune hemolytic anemia (AIHA), leading further investigation, intended to differentiate between the following diagnoses, 1) AIHA as a manifestation of systemic autoimmune disease; 2) AIHA as a paraneoplastic phenomenon, accompanying malignancy (either solid or hematologic); 3) Druginduced AIHA.

Abdominal CT scan (Fig. 1) revealed a diffuse retroperitoneal and mesenteric root soft tissue infiltration involving the splenic hilum and distal pancreas, engulfing the left kidney and adrenal, continuing along the left ureter into the pelvis, also surrounding the urinary bladder and the sigmoid colon. Mild lymphadenopathy (12 - $14 \mathrm{~mm}$ ) was seen in the retroperitoneum and mesentery. Mild ascites and bilateral hydronephrosis were also noted. After a PET-CT examination revealed the hyper-metabolic nature of disease, a CTguided, retroperitoneal lymph node biopsy was done. The pathology was consistent with NHL (low grade B-cell lymphoma, marginal zone).

Treatment was started during index hospitalization (RCVP - rituximab, cyclophosphamide, vincristine, prednisone), and later continued in an ambulatory setting of the hematology clinic with satisfactory response of the disease according to follow-up PET scan.

\section{Discussion}

The pattern of symptoms caused by systemic reactions to adjuvants has been gathered lately into ASIA syndrome [4].

The association of a lymphoproliferative disease and existence of silicone breast implants raised the suspicion that ASIA could be the causative process in this case.

Literature review reveals that a myriad of external stimuli have been associated with NHL pathogenesis.

\section{Infectious agents}

$\mathrm{HCV}$ infection is associated with chronic lymphocytes stimulation, B-cell mutations as well as direct oncogenic effect that have been proposed as the link between HCV and NHL [5]. Similarly, the effect of Helicobacter pylori on B-cell receptor (BCR) and activating mutations in the BCR pathway is one of the proposed mechanisms for emergence of mucosa-associated lymphoid tissue lymphoma [6]. Borrelia burgdorferi and Borrelia afzelii which are the causative agents of Lyme disease have been similarly linked with cutaneous lymphoma [7]. Burkitt lymphoma is thought to be triggered in Epstein-Barr virus (EBV)-infected patients. The viruses EBV and human herpesvirus 6B (HHV-6B) were also associated with diffuse large B-cell lymphoma in a large cohort of patients $[8,9]$.

\section{Autoimmune disorders}

Systemic lupus erythematosus (SLE), Sjogren's syndrome (SS) and rheumatoid arthritis were previously reported as risk factors for subsequent emergence of non-Hodgkin's Bcell lymphoma [10]. A several-fold increased risk for NHL seen in SLE versus the general population and the risk of lymphoma in patients with SS is 44 times higher than in the general population. Several studies estimated that $4-8 \%$ of patients with SS will develop lymphoma during the course of disease [11]. In a study by Martin and colleagues on salivary gland lymphoma in SS patients [12], rheumatoid factorproducing $\mathrm{B}$ cells have been suggested to be the mediators 
Table 1. Suggested Criteria for the Diagnosis of "ASIA"

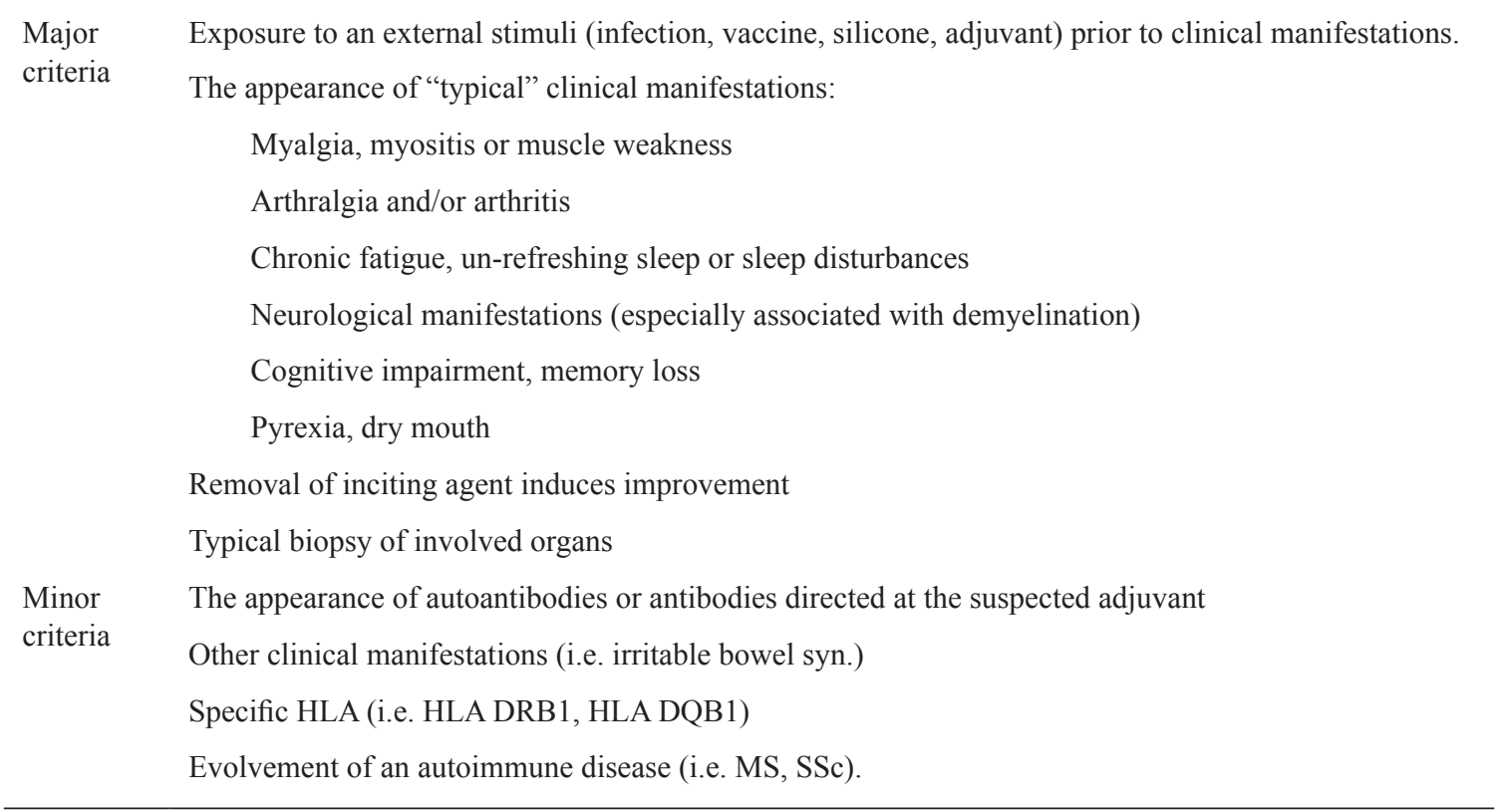

ASIA: autoimmune (auto-inflammatory) syndrome induced by adjuvants; HLA: human leukocyte antigen; MS: multiple sclerosis; SSc: systemic sclerosis.

of chronic $\operatorname{IgG}$ stimulation as well as $\operatorname{IgG}$ complexed to exoantigens. This pathophysiological pathway leads to the uncontrolled antigenic stimulation which makes them prone to mutations.

\section{ASIA and silicone implants}

ASIA syndrome is an array of autoimmune responses considered to evolve after, and result from chronic immune stimulation by adjuvants [13]. Establishment of diagnosis is based on existence of at least two major criteria or one major and two minor criteria [14] (Table 1).

In an 80 patients' Dutch cohort of patients with silicone breast implants $89 \%$ experienced fatigue, $74 \%$ neurasthenia, $69 \%$ joint pain, $65 \%$ muscle pain, $65 \%$ morning stiffness and $63 \%$ night sweats, post-implantation. Additionally, $14 \%$ developed confirmed autoimmune diseases at a median time of 7 years after first implantation. All patients had at least two major ASIA criteria and $79 \%$ fulfilled $\geq 3$ typical clinical manifestations. After explantation a significant reduction of symptoms was reported in 36 out of 52 women [14].

Associating the current emergence of lymphoma with the patient's silicone implants is almost inevitable. In a retrospective analysis of 100 women undergoing silicone breast implants explantation, for various reasons in Canada [15] the rate of explantation due to autoimmunity was $18 \%$ (of which SLE was diagnosed in $2 \%$, rheumatoid arthritis in $2 \%$, multiple sclerosis in $1 \%$, Raynaud's disease in $1 \%$, fibromyalgia in $10 \%$ and inflammatory arthritis in $2 \%$ of cases). The silicone itself, long thought to be biologically inert, is suspected to have a sensitizing effect on the patient's immune system. In a report from University of South Alabama [16], 100\% of patients who had their silicone filled implants removed due to complaints of arthlagia, fibromyalgia, xerophtalmia, xerostomia and amblyopia, were found to have established signs of chronic inflammation in the pathology slides of tissue samples taken during re-exploration procedure. In selfreported questionnaire taken post explantation a subjective symptoms improvement occurred over the course of months. Both ruptured capsule [17] and silicone gel-bleed are well described in the literature and recent reports suggest that "migration" of silicone gel to neighboring lymphatic system and skin may lead to systemic manifestations [18] of immune sensitization such as tender lymphadenopathy and skin lesions. Pericapsular biopsies from silicone-sensitized lymph nodes identified $\mathrm{T}$ cells which predominantly produced interleukin-17 [19], known for its role in numerous autoimmune and immune mediated inflammatory diseases $[20,21]$, as well as in lymphoid malignancies [22].

\section{Conclusion}

The association between autoimmunity symptoms and silicone breast implants as a predisposing factor to NHL is fascinating. Our patient had two major criteria of ASIA, namely, an exposure to an adjuvant and "typical" clinical manifesta- 
tions (i.e. arthralgia and arthritis) for several years prior to the diagnosis of NHL. We hypothesize that reversing the persistent inflammatory stimulation caused by an adjuvant, in our case silicone implants, may lead to lymphoma regression. In accord with previous recommendations [14-16], we suggest that explantation of the silicone-filled implants should be considered in an early stage when systemic symptoms or positive serology suggestive of an autoimmune/inflammatory disease appear in a patient with silicone-filled implants. Preventing chronicity is the assumed step in prevention of NHL in ASIA patients. This hypothesis requires further clinical investigation.

\section{Conflicts of Interest}

The authors declare that there are no conflicts of interest.

\section{References}

1. Zintzaras E, Voulgarelis M, Moutsopoulos HM. The risk of lymphoma development in autoimmune diseases: a meta-analysis. Arch Intern Med. 2005;165(20):23372344.

2. Farace F, Bulla A, Marongiu F, Campus GV, Tanda F, Lissia A, Cossu A, et al. Anaplastic large cell lymphoma of the breast arising around mammary implant capsule: an Italian report. Aesthetic Plast Surg. 2013;37(3):567-571.

3. American Food and Drug Administration website, Medical Devices section, Medical Devices safety tab, Safety Communication tab http://www.fda.gov/MedicalDevices/Safety/AlertsandNotices/ucm240000.htm. Accessed September 28, 2013.

4. Shoenfeld Y, Agmon-Levin N. 'ASIA' - autoimmune/ inflammatory syndrome induced by adjuvants. J Autoimmun. 2011;36(1):4-8.

5. Peveling-Oberhag J, Arcaini L, Hansmann ML, Zeuzem S. Hepatitis C-associated B-cell non-Hodgkin lymphomas. Epidemiology, molecular signature and clinical management. J Hepatol. 2013;59(1):169-177.

6. Isaacson PG, Du MQ. MALT lymphoma: from morphology to molecules. Nat Rev Cancer. 2004;4(8):644653.

7. Schollkopf C, Melbye M, Munksgaard L, Smedby KE, Rostgaard K, Glimelius B, Chang ET, et al. Borrelia infection and risk of non-Hodgkin lymphoma. Blood. 2008;111(12):5524-5529.

8. Mbulaiteye SM. Burkitt Lymphoma: beyond discoveries. Infect Agent Cancer. 2013;8(1):35.

9. Strong MJ, O'Grady T, Lin Z, Xu G, Baddoo M, Parsons $\mathrm{C}$, Zhang $\mathrm{K}$, et al. Epstein-Barr virus and human herpesvirus 6 detection in a non-Hodgkin's diffuse large B-cell lymphoma cohort by using RNA sequencing. J
Virol. 2013;87(23):13059-13062.

10. Dias C, Isenberg DA. Susceptibility of patients with rheumatic diseases to B-cell non-Hodgkin lymphoma. Nat Rev Rheumatol. 2011;7(6):360-368.

11. Voulgarelis M, Dafni UG, Isenberg DA, Moutsopoulos HM. Malignant lymphoma in primary Sjogren's syndrome: a multicenter, retrospective, clinical study by the European Concerted Action on Sjogren's Syndrome. Arthritis Rheum. 1999;42(8):1765-1772.

12. Martin T, Weber JC, Levallois H, Labouret N, Soley A, Koenig S, Korganow AS, et al. Salivary gland lymphomas in patients with Sjogren's syndrome may frequently develop from rheumatoid factor B cells. Arthritis Rheum. 2000;43(4):908-916.

13. Vera-Lastra O, Medina G, Cruz-Dominguez Mdel P, Jara LJ, Shoenfeld Y. Autoimmune/inflammatory syndrome induced by adjuvants (Shoenfeld's syndrome): clinical and immunological spectrum. Expert Rev Clin Immunol. 2013;9(4):361-373.

14. Maijers MC, de Blok CJ, Niessen FB, van der Veldt AA, Ritt MJ, Winters HA, Kramer MH, et al. Women with silicone breast implants and unexplained systemic symptoms: a descriptive cohort study. Neth J Med. 2013;71(10):534-540.

15. Peters W, Smith D, Fornasier V, Lugowski S, Ibanez D. An outcome analysis of 100 women after explantation of silicone gel breast implants. Ann Plast Surg. 1997;39(1):9-19.

16. Thomas WO, 3rd, Harper LL, Wong SW, Michalski JP, Harris CN, Moore JT, Rodning CB. Explantation of silicone breast implants. Am Surg. 1997;63(5):421-429.

17. Handel N, Garcia ME, Wixtrom R. Breast implant rupture: causes, incidence, clinical impact, and management. Plast Reconstr Surg. 2013;132(5):1128-1137.

18. Cawrse NH, Pickford MA. Cutaneous manifestation of silicone dissemination from a PIP implant--a case for prophylactic explantation? J Plast Reconstr Aesthet Surg. 2011;64(8):e208-209.

19. Wolfram D, Rabensteiner E, Grundtman C, Bock G, Mayerl C, Parson W, Almanzar G, et al. T regulatory cells and TH17 cells in peri-silicone implant capsular fibrosis. Plast Reconstr Surg. 2012;129(2):327e-337e.

20. van den Berg WB, McInnes IB. Th17 cells and IL-17 a-focus on immunopathogenesis and immunotherapeutics. Semin Arthritis Rheum. 2013;43(2):158-170.

21. Dolff S, Abdulahad WH, Westra J, Doornbos-van der Meer B, Limburg PC, Kallenberg CG, Bijl M. Increase in IL-21 producing T-cells in patients with systemic lupus erythematosus. Arthritis Res Ther. 2011;13(5):R157.

22. Fontao L, Brembilla NC, Masouye I, Kaya G, Prins C, Dupin N, Saurat JH, et al. Interleukin-17 expression in neutrophils and Th17 cells in cutaneous T-cell lymphoma associated with neutrophilic infiltrate of the skin. $\mathrm{Br}$ J Dermatol. 2012;166(3):687-689. 